\title{
Cathode Structure Optimization and Process Experiment in Electrochemical Machining of Multi- stage Internal Cone Hole
}

\section{Lin Tang ( $\square$ tang_lin168@126.com )}

Xi'an Technological University

\section{Wenli Yang}

Xi'an Technological University

\section{Chengjin Shi}

Xi'an Kunlun Industry Group Co. Ltd

\section{Lifeng Zhang}

China North Industries Group North Group Inner Mongolia North Heavy Industry Group Corp, Ltd

\section{Kaige Zhai}

Xi'an Technological University

\section{Research Article}

Keywords: multi-stage internal cone hole, electrochemical machining (ECM), cathode optimization, technological experiment

Posted Date: October 22nd, 2021

DOl: https://doi.org/10.21203/rs.3.rs-994118/v1

License: (c) (i) This work is licensed under a Creative Commons Attribution 4.0 International License. Read Full License

Version of Record: A version of this preprint was published at The International Journal of Advanced Manufacturing Technology on March 11th, 2022. See the published version at https://doi.org/10.1007/s00170-021-08558-2. 


\title{
Cathode Structure Optimization and Process Experiment in Electrochemical Machining of Multi-stage Internal Cone Hole
}

\section{Lin Tang $\cdot$ Wenli Yang $\cdot$ Chengjin Shi $\cdot$ Lifeng Zhang $\cdot$ Kaige Zhai}

\begin{abstract}
In order to solve the problems of uneven gap distribution and flow pattern in complex parts with multi-stage internal cone holes in electrochemical machining, a method of computer simulation assisted cathode design was proposed. The electric field and flow field models of machining gaps were established respectively, and the simulation of different cathode profiles was carried out. When the cathode cone angle is $2^{\circ}$, the electric field distribution between the cathode and the workpiece is reasonable, and the electrolyte distribution in the machining gap is uniform. With the conditions of processing voltage $10 \mathrm{~V}$, electrolyte inlet pressure $1.5 \mathrm{MPa}$, electrolyte temperature $28{ }^{\circ} \mathrm{C}$ and cathode feed speed $5 \mathrm{~mm} / \mathrm{min}$, the ECM processing of multi-stage internal cone hole was carried out by using the optimized cathode. The results show that the surface of the workpiece has no flow pattern, the dimensional forming accuracy is better than $0.1 \mathrm{~mm}$, and the surface roughness reaches $\mathrm{Ra} 0.697 \mu \mathrm{m}$. Research shows that the optimization of cathode structure with computer simulation can shorten the cathode development cycle and reduce the cost of cathode design effectively in ECM, which provides an efficient and feasible method for the optimization of complex cathode structure.
\end{abstract}

Key Words: multi-stage internal cone hole; electrochemical machining (ECM); cathode optimization; technological experiment

\section{Introduction}

With the rapid development of modern industry, in many fields such as aerospace, weapon equipment, biomedicine, mechanical engineering, etc. The demand for complex and integral parts with hole structures is increasing [1-4]. As an important machining process that accounts for a large proportion of machining, about one-third of the machining volume is used for hole structure processing, which takes about a quarter of the total machining time [5]. Hole making technology has become an important part of modern manufacturing technology, especially the processing of large aspect ratio, complex structure and taper hole structure. The integral components with multi-stage internal cone hole are formed by connecting internal holes of different diameters through the taper angle, which have the advantages of light and compact. However, the processing is very difficult. Not only the processing surface is required to be complete and defect-free, but also the radial and axial direction has very high dimensional accuracy requirements. The existing machining technology has some problems, such as low production efficiency, poor surface quality and difficulty in precise control of taper, which cannot meet the actual needs. There have been some researches on the processing methods and processes of tapered hole parts with variable cross-sections, but new processing methods for tapered hole structures with variable cross-sections of special difficult-to-machine materials are rarely involved [6,7]. Electrochemical machining (ECM) has the advantages of one-time forming, high processing efficiency, good surface quality and no loss of cathode in theory, which determines that ECM is one of the effective methods to realize the machining of conical hole structure parts [8-12].

A large number of scholars have carried out a lot of researches on the problem of low forming

\section{Lin Tang $(\square) \cdot$ Wenli Yang $\cdot$ Chengjin Shi $\cdot$ Lifeng Zhang $\cdot$ Kaige Zhai}

School of Mechatronics Engineering, Xi'an Technological University, 710021 Xi'an, People's Republic of China

E-mail: tang_lin168@126.com 
precision and poor surface quality for hole parts.

For processing technology, Ma et al. fabricated the non-circular hole structure on the surface of turbine rotor blade by using the combined electrical machining technology [13]. Sathish used the injector nozzle to drill micro holes in pure stainless steel. Considering the process parameters such as feed speed, voltage and duty cycle, the process parameters of stainless steel micro drilling were optimized, and the taper of micro holes was analyzed by VMS series optical image measuring instrument [14]. Zhao designed a flow field model with a variety of flow channel characteristics for the electrochemical machining of diamond-shaped holes. The method of combining short arc flow channel and vibrating feed was adopted, which significantly improved the accuracy of machining positioning and the stability of the machining process [15]. Zhao et al. proposes a packet pulse-matched composite feed mode based on linear feed and composite feed modes, which optimizes the process stability and localization of diamond holes markedly [16]. Zhu et al. proposed a new method of machining small holes which called ultrasonic-assisted electrochemical drill-grinding, studied the simulation of electrochemical drill-grinding process to illustrate the effect of ball-end electrode on reducing the hole taper. Finally, small holes with taper of less than 0.6 degree were machined [17]. Biplab et al. presented a novel combination of micro-ECDM drilling and micro-ECM finishing for producing micro-holes in SS-304 stainless steel, and carried out the experiment which indicates a reduction in hole taper angle, improved circularity and surface quality [18]. Xu et al. presented a hybrid process called tube electrode high-speed electrochemical discharge drilling that combines electrical discharge high-speed drilling and electrochemical machining, which can fabricate a small hole with low tool wear and almost no recast layer by the hybrid process [19]. In addition, some scholars have proposed various algorithms for optimizing process parameters to improve the accuracy of predicting processing results, which helps to shorten the cycle of optimizing process parameters and save manufacturing costs [20-22].

For cathode designing and structure, Uchiyama et al. carried out the numerical analysis of the electrostatic field and large deflection in the ECM of the curved hole structure, designed and optimized the cathode, reduced the radius of curvature, and improved the processing efficiency [23]. Burger et al. studied the electrochemical machining characteristics of LEK94 nickel-based single crystal material, optimized the processing parameters, and designed a special electrode for tapered holes, which realized the finishing of the tapered micro-holes of LEK94 material [24]. By simulating and analyzing the distribution of potential and current density on the cathode surface and electrolyte, Mi et al. designed a copy-shaped tool cathode with a gradually decreasing conductive area, and successfully processed a reverse tapered hole [25]. Kong et al. presented a novel method for preparing an insulation layer by asymmetric-timed bipolar electrophoretic coating in an aqueous epoxy acrylic solution to solve the problem that the prepared insulation layer is easily damaged under the influence of high-pressure liquid flushing and bubble tearing, the taper of machined holes are reduced by more than $60 \%$, and the surface quality is improved by about $30 \%$, compared to the holes machined with the traditional electrodes [26]. Li et al. designed the tubular electrode and used the pulse electrochemical machining method to process the hole with variable cross-section, whose parameters meet the design requirements [27]. Hourng et al. designed a cathode with a diameter of $100 \mu \mathrm{m}$ and used a rotating feed method to conduct electrochemical machining of micropores [28]. Selvarajan et al. used copper electrodes to process Al7075 material by pulse electrochemical machining, and studied the influence of electrolyte concentration, pulse duty cycle, and machining voltage on the actual machining effect [29]. Ramezanali et al. carried out the cathode design of the special tool for electrochemical machining of the spiral in the small-caliber barrel [30]. In addition, the application of computer-aided design and finite element 
method in cathode design speeds up the design work, which can effectively reduce the cost of electrochemical processing and improve processing efficiency [31-33].

The structure of the multi-stage internal cone hole studied in this paper is shown in Fig. 1. The movable cathode is used to realize the processing of this structure. For the electrochemical machining of the multi-stage internal cone hole, due to the large span of the taper hole size, it is easy to cause uneven distribution of the gap between the machining gap, which affects the forming accuracy and surface quality. As shown in Fig. 2, the surface of the sample processed with an equal gap cathode produces serious flow lines, and the second cone tail end has an extremely poor molding size. In order to improve the forming accuracy and surface quality of the parts, this paper uses computer simulation methods to simulate the electric field and flow field of the cathodes with different processing profiles, optimized the cathode profiles and carried out process experiments. A multi-stage internal cone hole part that meets the design requirements was processed finally.

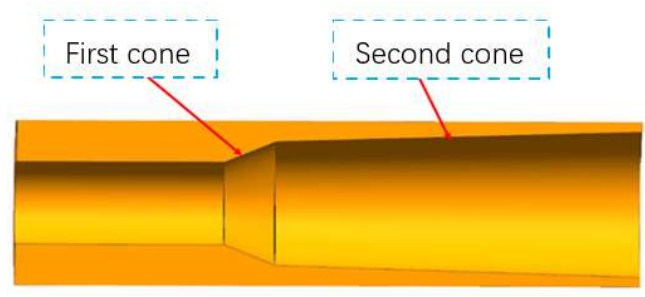

Fig.1 Structure of multi-stage internal cone hole

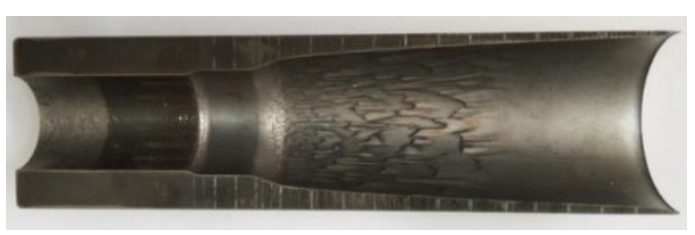

Fig.2 Sample processed with equal gap cathode

\section{Establishment of cathode model}

The size of multi-stage internal cone hole is narrowed by width, and the gap flow field is easy to change and uneven in the process of machining. When designing the cathode, the pre-machined cone section is designed according to the initial blank size of the workpiece, and then the first and second cone processing sections are designed according to the design size of the parts. The processing of the multi-stage internal cone hole is a two-dimensional derivative electrolytic processing, where the workpiece doesn't move and the cathode needs to feed. At the end of the processing, the cathode forming section is required to be in the cone hole of the workpiece, and it must ensure that the cathode stops feeding and the size meets the requirements of designing. Compared with through hole processing, in addition to the continuous change of radial processing gap, there is also side wall cone angles in the axis. The difficulty is to ensure the shape size of the pre-processed section, realize the orderly connection of first and second cone, and finally ensure that each section meets the requirements. Based on the principle that the removal depth of one side is proportional to the length of the cathode during full-cone cathode processing, under equal gap processing conditions, the cathode working section is divided into four sections, namely the pre-processed cone, the insulating section, the first cone processing section, and the second cone processing section, as shown in Fig. 3.

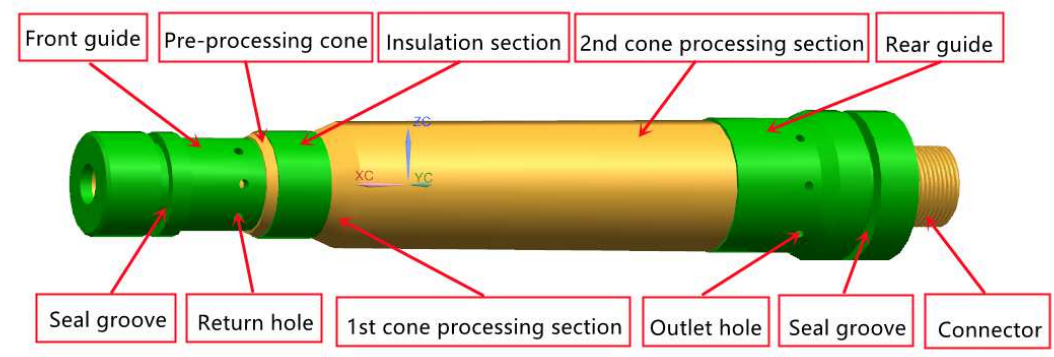


Fig.3 Cathode structure of multi-stage internal cone hole for ECM

\section{Simulation of gap electric field in ECM of multi-step internal cone hole}

In the multi-stage internal cone hole machining, the forming of the second cone surface of workpiece is the most difficult to control. After the reaming is completed, the angle of the second cone processing section determines the real-time machining gap and the distribution of electric field in ECM, which affect the dissolution rate of workpiece directly, so the formation of the second cone surface is mainly guaranteed by the angle of the second cone processing section. By analyzing the current density distribution of different cathode profiles during processing, the cathode profile structure which suits for this research object is selected.

\subsection{Establishment of simulation model of the gap electric field}

\section{(1) Establishment of mathematical model}

The model studied in this paper does not include the power. The gap electric field is treated as a passive electric field, and the electric field potential distribution of the gap satisfies the Laplace equation.

$$
\frac{\partial^{2} \varphi}{\partial x^{2}}+\frac{\partial^{2} \varphi}{\partial y^{2}}+\frac{\partial^{2} \varphi}{\partial z^{2}}=0
$$

The electric field distribution of the gap in ECM of the multi-stage internal cone hole is shown in Fig. 4.

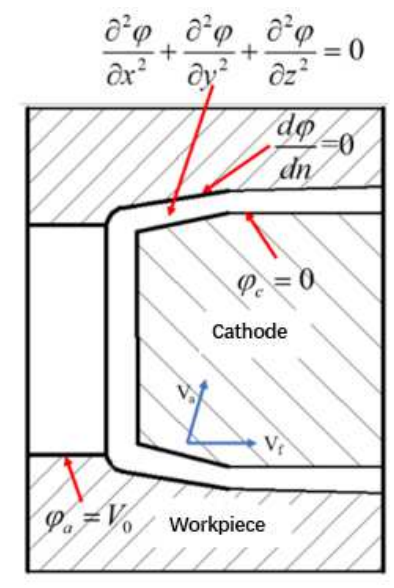

Fig.4 Mathematical model of electric field distribution

In the formula, $\mathrm{x}, \mathrm{y}, \mathrm{z} \longrightarrow$ respectively the coordinates of each point in the machining gap, unit: $\mathrm{mm}$.

The current density of the machining gap is

$$
\vec{J}=\kappa \vec{E}
$$

In the formula,

$\vec{J}$ gradient of current density distribution in machining gap, unit: $\mathrm{A} / \mathrm{cm} 2$;

$\vec{E}$ gradient of the potential distribution of the machining gap, unit: V/m.

$$
\vec{E}=-\frac{d \varphi}{d n} n
$$


In the formula,

$\varphi$ __ectric potential, unit: $\mathrm{V}$;

$\mathrm{n} \longrightarrow$ normal component.

When reaching the equilibrium processing state, the removal rate of workpiece on the processed surface is:

$$
v_{a}=\eta \omega J=v_{f} \cos \theta
$$

When the electrolytic surface of the workpiece is perpendicular to the direction of the cathode feeding, $\theta=0^{\circ}$, that is,

$$
v_{a}=\eta \omega J=v_{f}
$$

Considering only the relationship between the values of the conductivity $\kappa$ and $\vec{E}$, the potential gradient around the surface of the artifact anode is:

$$
\frac{d \varphi}{d n}=\frac{\eta_{0} J_{0}}{\eta \kappa} \cos \theta
$$

\section{(2) Establishment of finite element model}

Due to the large taper difference between the two ends of the multi-stage internal cone holes, the cathode profile was gradually modified, which requires continuous optimization and iteration. According to the angle between the extension line of the second cone surface and the axis, the cathode model with equal clearance normal cone $\left(-1^{\circ}\right)$ and the angle of the processing section of the second cone were designed with $0^{\circ}, 1^{\circ}$ and $2^{\circ}$ respectively. The four cathode models are shown in Fig. 5.

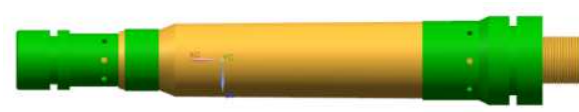

a) $-1^{\circ}$

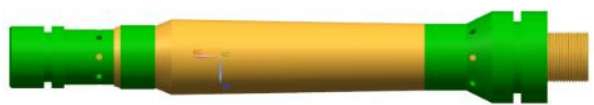

c) $1^{\circ}$

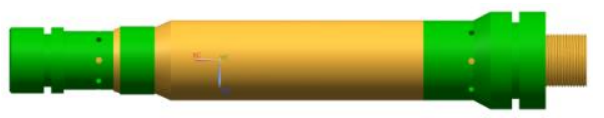

b) $0^{\circ}$

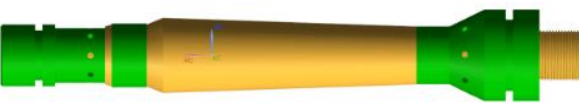

d) $2^{\circ}$

Fig.5 Cathode with different second cone angle

In the process of electrochemical machining, the positive and negative poles of the DC power supply are respectively connected with the workpiece and cathode, and the two equipotential surfaces form electric fields in the machining gap. Therefore, the electric field boundary conditions are: the cathode potential is 0 , and the anode potential is the processing voltage $\mathrm{V}_{0}$.

$$
\begin{aligned}
& \varphi_{c}=0 \\
& \varphi_{a}=V_{0}
\end{aligned}
$$

\subsection{Analysis of current density simulation results}

Under the condition of voltage of $10 \mathrm{~V}$, the electric field simulation was carried out on the machining gap after the cathode with different machining surfaces completely entered the workpiece. The current density distribution of the machining gap of the second cone at different angles is shown in Fig. 6. As can be seen from Fig. 6a), when the cathode is a normal cone with equal gap, the current density of machining gap is evenly distributed, and the current density at the tail end of the second cone is 
$1.3 \times 10^{5} \mathrm{~A} / \mathrm{m}^{2}$. In mobile electrochemical machining, the second cone tail end of the workpiece is processed for the longest time. With the continuous feeding of the cathode, the current density of the second cone tail end does not decrease, so as the second cone will continue to be processed after forming, resulting in too much erosion of the second cone tail end, and the size of the workpiece is too large after processing.

When the second cone angle of $0^{\circ}$, namely the second cone cathode body for the standard cylinder, the current density distribution of the machining gap as shown in Fig. 6b), second cone tail current density is $8.1 \times 10^{4} \mathrm{~A} / \mathrm{m}^{2}$. It can be seen that with the gradual increase of the angle of the second cone, the machining gap gradually expands, and the current density distribution from the first cone to the second cone presents a decreasing trend, the removal velocity of the tail end of the second cone decreases, which can improve the problem of the end size of the workpiece after machining. When the angle of the second cone of the cathode is $1^{\circ}$, the simulation result of the electric field of the machining gap is shown in Fig. 6c). The current density of the tail end of the second cone of the workpiece is $3.7 \times 10^{4} \mathrm{~A} / \mathrm{m}^{2}$, and the removal rate of the second cone end of the workpiece continues to decrease during the processing. When the angle of the second cone of the cathode is $2^{\circ}$, the electric field simulation result of the machining gap is shown in Fig. 6d), and the current density of the tail end of the second cone of the workpiece is $2.4 \times 10^{4} \mathrm{~A} / \mathrm{m}^{2}$. It can be seen from the current density distribution cloud that the removal rate of the second cone tail of the workpiece will decrease greatly with the process of machining.

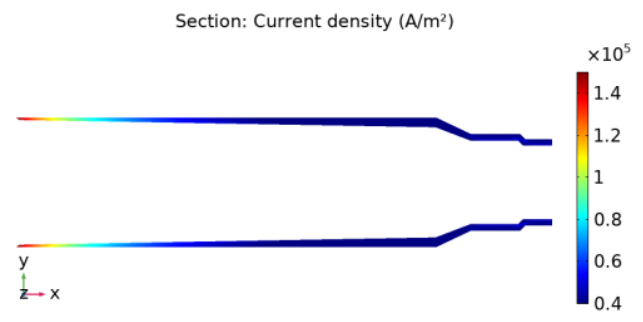

a) The angle of the second cone is $-1^{\circ}$

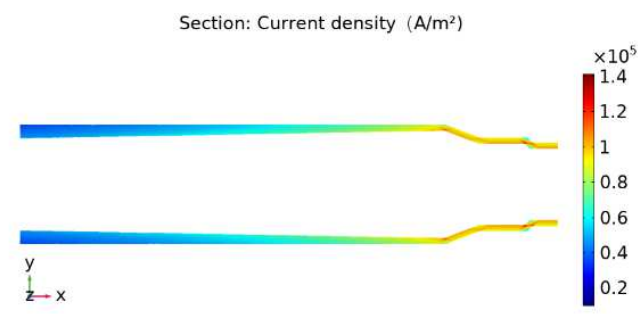

c) The angle of the second cone is $1^{\circ}$

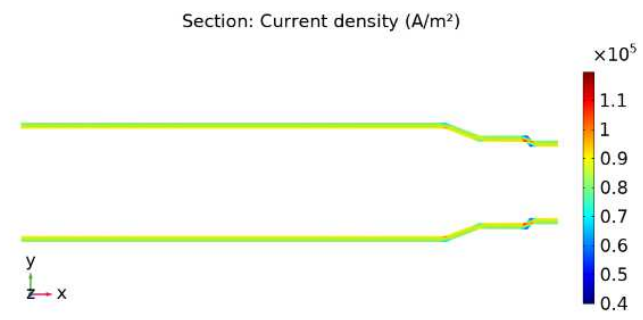

b) The angle of the second cone is $0^{\circ}$

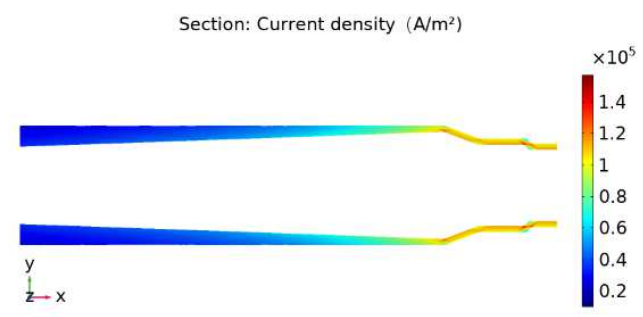

d) The angle of the second cone is $2^{\circ}$

Fig.6 Nephogram of gap current density for different cathode profiles

With the increase of the angle of the second cone, the electric field distribution becomes more concentrated and the gradient of the current density distribution in the machining gap becomes more obvious. In view of this result, points on the workpiece surface within the machining gap of the second cone tail end were selected. The current density of the second cone tail end at different angles is shown in Fig. 7. 


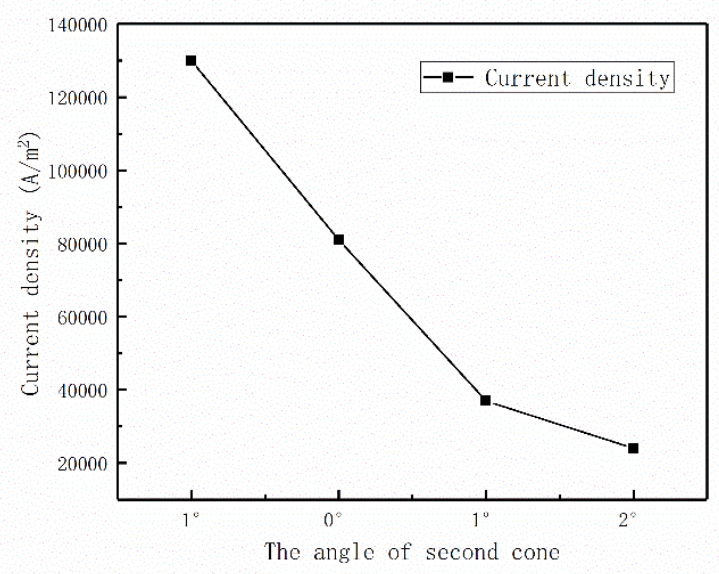

Fig.7 The tail current density of the second cone at different angles

\section{Simulation of gap flow field in ECM of multi-stage internal cone hole}

The taper size span of multi-stage internal cone holes is large, and the forming rules of different cone angles are different in the process of ECM. The electrolyte flow field is easy to mutate in the machining gap and form beam, resulting in flow lines on the surface of multi-stage internal cone holes. The simulation analysis of the influence for different cathode types on the flow field of ECM provide theoretical guidance for the later cathode optimization process.

\subsection{Establishment of the simulation mathematical model of the gap flow field}

In mobile electrochemical machining, machining gap is constantly changing, affected by electrolyte flow, current, temperature and other factors. In order to facilitate the study, the machining gap is assumed to be an ideal state, the electrolyte is incompressible fluid without bubbles, and the influence of solid particles in the gap is ignored. The dynamic viscosity does not change with the change of velocity. Ignoring the influence of temperature changes, assuming that the machining gap temperature is constant at $30^{\circ} \mathrm{C}$; the electrolyte is $5 \% \mathrm{NaCl}+16 \% \mathrm{NaNO}_{3}+4 \% \mathrm{NaClO}_{3}$ composite electrolyte, the dynamic viscosity coefficient $\mu$ is $1.01 \times 10^{-3} \mathrm{~Pa} \cdot \mathrm{s}$, and the density $\rho$ is $1.11 \times 10^{3} \mathrm{Kg} / \mathrm{m}^{3}$, the machining process is steady.

The electrolyte does not travel a long distance in the processing area, and its flow is restricted by the law of conservation of mass and the law of conservation of momentum, and the flow model satisfies the Navier-Stokes equation,

$$
\begin{gathered}
\rho(u \cdot \nabla) u=\nabla \cdot[-\rho I+K]+F \\
\rho \nabla \cdot(u)=0
\end{gathered}
$$

Where, $\rho$ is the electrolyte density; u is the electrolyte flow velocity; I is the unit tensor; F is the volume force of the fluid per unit mass. The volume force $\mathrm{F}$ received by the electrolyte in the machining gap is extremely small and can be ignored.

$$
K=\left(\mu+\mu_{T}\right)\left(\nabla u+(\nabla u)^{T}\right)
$$

Based on the above assumptions, the standard $\mathrm{k}-\varepsilon$ model was used to calculate the flow field distribution in machining gap. The model introduces two additional dependent variables: turbulent kinetic energy $\mathrm{k}$ and turbulent dissipation rate $\varepsilon$. Turbulent viscosity is

$$
\mu_{T}=\rho C_{\mu} \frac{k^{2}}{\varepsilon}
$$

Where, $C_{\mu}$ is the model constant.

The transmission equation of $\mathrm{k}$ is as follow 


$$
\rho \frac{\partial k}{\partial t}+\rho u \cdot \nabla k=\nabla\left(\left(\mu+\frac{\mu_{T}}{\sigma_{k}}\right) \nabla k\right)+P_{k}-\rho \varepsilon
$$

The transmission equation of $\varepsilon$ is as follow

$$
\rho \frac{\partial \varepsilon}{\partial t}+\rho u \cdot \nabla \varepsilon=\nabla \cdot\left(\left(\mu+\frac{\mu_{T}}{\sigma_{\varepsilon}}\right) \nabla \varepsilon\right)+C_{\varepsilon 1} \frac{\varepsilon}{k} P_{k}-C_{\varepsilon 2} \rho \frac{\varepsilon^{2}}{k}
$$

Where, turbulence generates term is

$$
P_{k}=\mu_{T}\left(\nabla u:\left(\nabla u+(\nabla u)^{T}\right)-\frac{2}{3}(\nabla \cdot u)^{2}\right)-\frac{2}{3} \rho k \nabla \cdot u
$$

The model constant values in the formula are shown in Table 1.

Tab. 1 Constants in the standard k- $\varepsilon$ model

\begin{tabular}{ccccccc}
\hline Constant & $C_{C 1}$ & $C_{C 2}$ & $C_{\mu}$ & $\sigma_{k}$ & $\sigma_{\varepsilon}$ & $\mathrm{K}$ \\
\hline Value & 1.44 & 1.92 & 0.09 & 1.0 & 1.3 & 0.41 \\
\hline
\end{tabular}

\subsection{Analysis of simulation results of gap flow field}

The simulation results are shown in Fig. 8. In Fig. 8a), when the cathode second cone processing section is normal cone $-1^{\circ}$ of equal gap, the electrolyte flow velocity of the second cone in the machining gap is polarized seriously. In Fig. 8b), when the angle of the second cone processing section is $0^{\circ}$, the polarization degree of electrolyte flow velocity is alleviated compared with normal cone $-1^{\circ}$ of equal gap, and the electrolyte flow velocity increased. In Fig. 8c), when the second cone processing section is a $1^{\circ}$ inverted cone profile, the electrolyte flow rate continued to increase, and the flow rate became more uniform in the second cone section. In Fig. 8d), when the second cone processing section is a $2^{\circ}$ inverted cone profile, the electrolyte flow rate of the second cone section in machining gap is more uniform compared with the other three cathode profiles, and presents a trend of continuous increase. The simulation results show that with the change of the second cone angle from $-1^{\circ}$ to $2^{\circ}$, the flow velocity of electrolyte increases gradually, and the flow field presents a gradually uniform trend.

Contour: Velocity $(\mathrm{m} / \mathrm{s})$

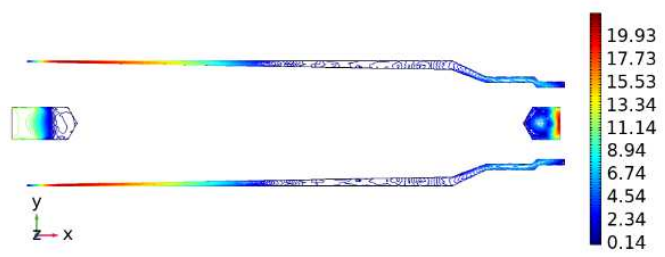

a) The angle of the second cone is $-1^{\circ}$

$$
\text { Contour: Velocity }(\mathrm{m} / \mathrm{s})
$$

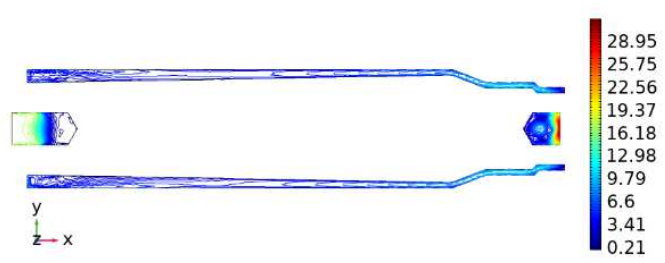

c) The angle of the second cone is $1^{\circ}$
Contour: Velocity $(\mathrm{m} / \mathrm{s})$

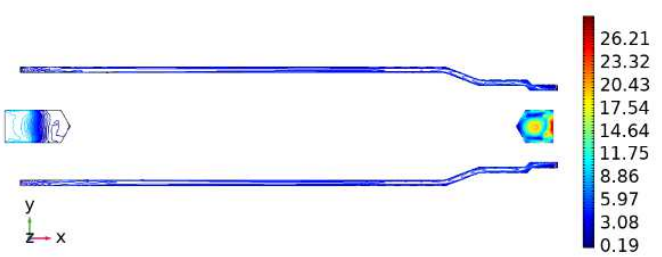

b) The angle of the second cone is $0^{\circ}$

Contour: Velocity $(\mathrm{m} / \mathrm{s})$

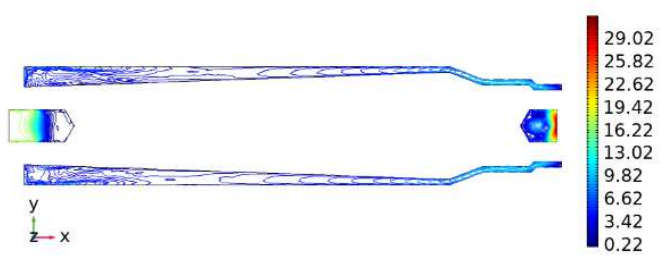

d) The angle of the second cone is $2^{\circ}$

Fig.8 Contour plots of gap flow field for different cathode profiles 
The flow field simulation results of different cathode profiles fully show that changing the second cone angle of the cathode can significantly improve the gap flow field distribution for ECM and effectively reduce the beam generation caused by the uneven distribution of the electrolyte in the machining gap.

\section{Experiments on ECM of multi-stage internal cone holes with different cathode profiles}

Testing equipment for multi-stage internal cone-shaped integral components is a large-scale horizontal CNC electrochemical machining system independently developed, as shown in Fig. 9. The system mainly includes: machine bed, power supply system, control system, cooling system, electrolyte circulation system, filtration system, etc.

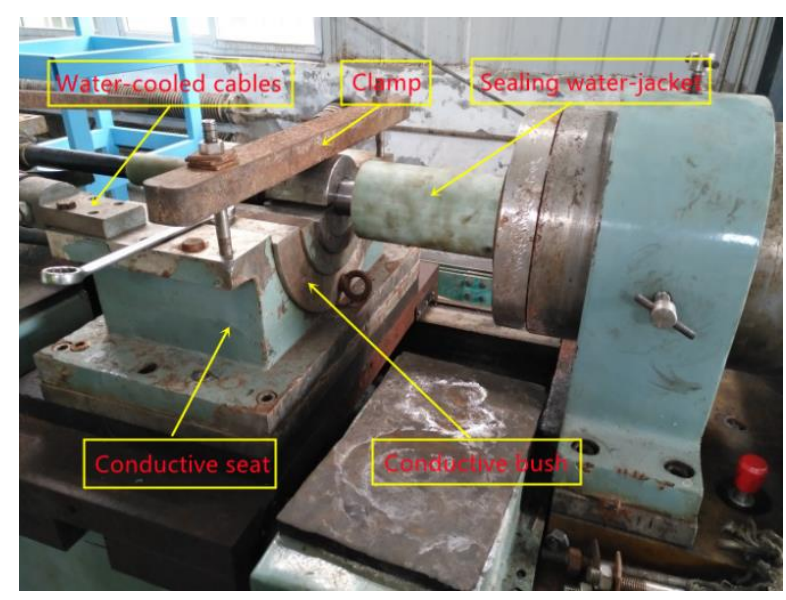

Fig.9 Horizontal ECM System of CNC

The normal cone cathode with equal gap before optimization and the cathode with reversed-cone after optimization were used respectively, as shown in Fig. 10, to carry out the experimental research on the process of multi-stage internal cone hole. Using $5 \% \mathrm{NaCl}+16 \% \mathrm{NaNO}_{3}+4 \% \mathrm{NaClO}_{3}$ composite electrolyte, under the conditions of processing voltage of $10 \mathrm{~V}$, electrolyte inlet pressure of $1.5 \mathrm{MPa}$, electrolyte temperature of $28^{\circ} \mathrm{C}$, and cathode feed speed of $5 \mathrm{~mm} / \mathrm{min}$, the section of the processed sample is shown in Fig.11.

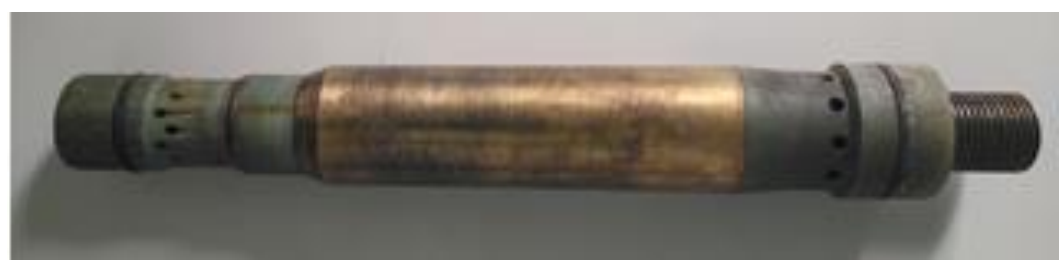

a) Equal gap normal cone cathode

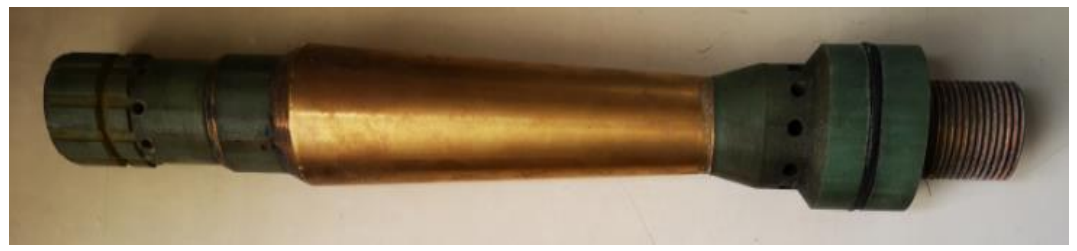

b) Inverted cone cathode after optimizing the profile

Fig.10 Cathode 


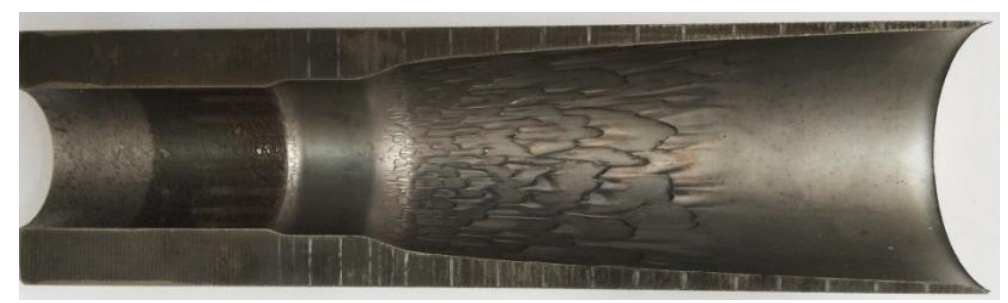

a) Machining sample of normal cone cathode with equal gap

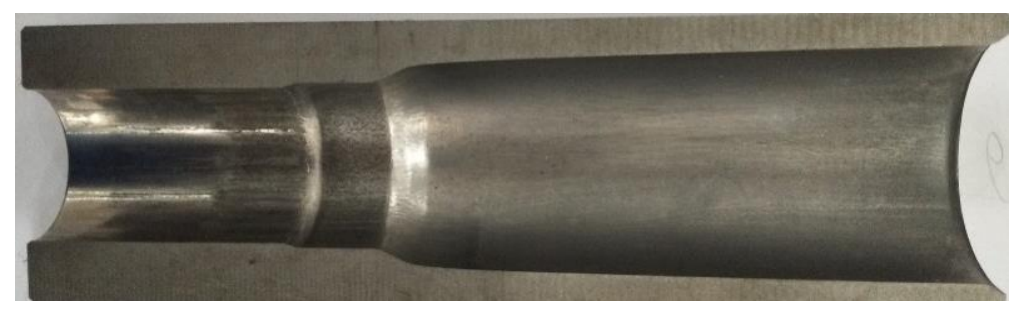

b) Machining sample of inverted cone $2^{\circ}$ cathode after optimized

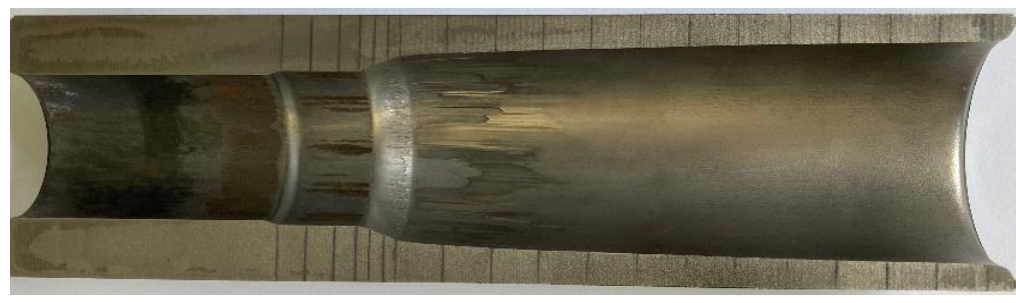

c) Machining sample of inverted cone $3^{\circ}$ cathode after optimized

Fig.11 Machining samples

Under the same processing parameters, the surface of the sample processed by the equal-gap normal cone cathode has serious flow lines, and the tail end size is out of tolerance; the surface of the sample processed by the optimized inverted cone $2^{\circ}$ cathode has no flow lines; the surface of the sample processed by the optimized inverted cone $3^{\circ}$ cathode has light flow lines, and the tail end erosion is insufficient, the processing size does not meet the design requirements. The surface of the sample processed by the inverted cone $2^{\circ}$ cathode was cleaned, and the internal diameter dial indicator was used to measure the sampling points in sections. The measurement result of the sample size is shown in Fig.12. The sample size processed by the inverted cone $2^{\circ}$ cathode is close to the design size of the multi-stage internal cone hole, and the maximum error is better than $0.1 \mathrm{~mm}$.

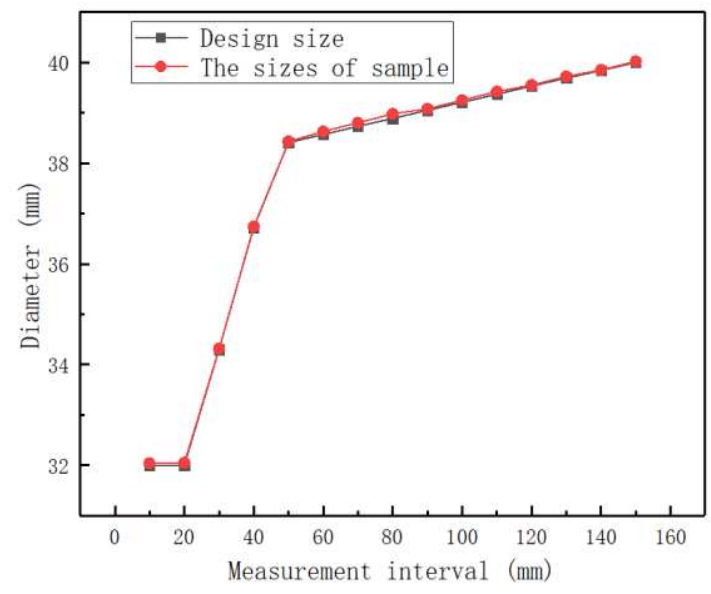

Fig.12 Measuring result of the sample's size 
To facilitate measurement, a small piece of the sample machined by the inverted cone $2^{\circ}$ cathode was cut on the linear cutting machine and placed on the ZYGO Plus test platform of the white light interferometer, as shown in Fig. 13, to measure the surface roughness. The result is shown in Fig. 14 with the value of $\mathrm{Ra} 0.697 \mu \mathrm{m}$.

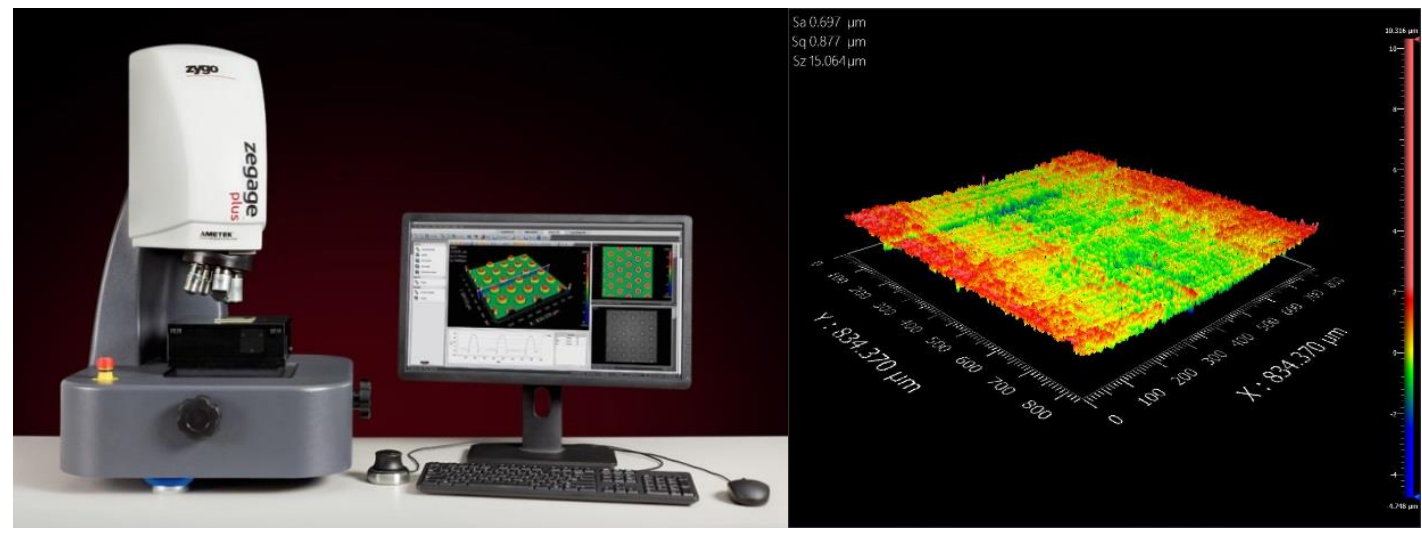

Fig.13 White light interferometer of ZYGO

Fig.14 Testing result of surface roughness

\section{Conclusions}

In this paper, the gap electric field and flow field simulation research are carried out for multi-stage internal cone hole ECM, the cathode was optimized, and the multi-stage internal cone hole ECM process test was carried out. The following conclusions were obtained:

(1) When the inverted cone angle is $2^{\circ}$, it can effectively reduce the secondary machining of the second cone end of the workpiece as the cathode feeding, and making the electrolyte flow field uniformly distributed in the gap at the same time, which can reduce or even eliminate the flow pattern on the surface of the multi-stage internal cone hole;

(2) Under the processing conditions of composite electrolyte $5 \% \mathrm{NaCl}+16 \% \mathrm{NaNO}_{3}+4 \%$ $\mathrm{NaClO}_{3}$, the machining voltage $10 \mathrm{~V}$, electrolyte temperature $28{ }^{\circ} \mathrm{C}$, electrolyte pressure of $1.5 \mathrm{MPa}$, the cathode feed rate of $5 \mathrm{~mm} / \mathrm{min}$. The typical parts with multi-stage internal cone hole with surface roughness of $\mathrm{Ra} 0.697 \mu \mathrm{m}$ were processed stably, the dimensional accuracy is better than $0.1 \mathrm{~mm}$;

(3) The cathode optimization assisted by computer simulation can effectively shorten the development cycle and reduce the design cost, which provides an efficient and feasible method for the complex cathode structure optimization in ECM.

\section{Authors' contribution}

Lin Tang was the main contributor and corresponding author of the manuscript. Professor Lin Tang designed the research process, and led Wenli Yang and Kaige Zhai to conduct the cathode structure optimization and process experiment in electrochemical machining of multi-stage internal cone hole. Chengjin Shi and Lifeng Zhang participated in the experimental study and guided the manuscript writing.

\section{Funding information}

This work was financially supported by Shaanxi Province Key Research and Development projects (Grant No. 2020GY-153) and Shaanxi University Youth Innovation Team Project (Grant No. 20201020).

\section{Availability of data and materials}


All data generated or analysed during this study are included in this published article.

\section{Declarations}

\section{Ethics approval}

Not applicable.

\section{Consent to participate}

Not applicable.

\section{Consent for publication}

Not applicable.

\section{Conflict of interest}

The authors declare no competing interests.

\section{Reference}

[1] Rajurkar K.P, Levy G, Malshe A, Sundaram M.M, McGeough J, Hu X, Resnick R, DeSilva A (2006) Micro and Nano Machining by Electro Physical and Chemical Processes. Annals of the CIRP 55(2):643-666.

[2] Zhang Y, Xu ZY, Zhu D, Qu NS, Zhu Y (2016) Drilling of film cooling holes by a EDM/ECM in situ combined process using internal and side flushing of tubular electrode. The International Journal of Advanced Manufacturing Technology 83(1-4): 505-517.

[3] Li ZY, Wei XT, Sun JJ, Zang CW, Fu CH (2016) Process capability and effect size of vacuum extraction shaped tube electrolytic drilling of Inconel alloy for high-performance cooling hole. The International Journal of Advanced Manufacturing Technology 85(9-12):2557-2566.

[4] Chai MX, Li ZY, Yan HJ, Huang ZX (2020) Flow field characteristics analysis of interelectrode gap in electrochemical machining of film cooling holes. The International Journal of Advanced Manufacturing Technology 112(1-2):525-536.

[5] Ai DM, Jia ZX(2000) Development status of small hole machining techno-logy. Mechanical Engineer (1) 8-10. (in Chinese)

[6] Shimasaki T, Kunieda M (2016) Study on influences of bubbles on ECM gap phenomena using transparent electrode. CIRP Annals 65(1):225-228.

[7] Liu Y, Qu NS (2020) Investigation on the performance of macro electrochemical machining of the end face of cylindrical parts. International Journal of Mechanical Sciences 169(C).

[8] Sen M, Shan H.S (2004) A review of electrochemical micro-hole drilling processes. International Journal of Machine Tools and Manufacture 45( 2) : 137-152.

[9] El-Hofy H (2019) Vibration-assisted electrochemical machining: a review. The International Journal of Advanced Manufacturing Technology, 2019, 105(1-4): 579-593.

[10] Klocke F, Klink A, Veselovac D, Aspinwall D.K, Soo S.L, Schmidt M, Schilp J, Levy G, Kruth J (2014) 
Turbomachinery component manufacture by application of electrochemical, electro-physical and photonic processes. CIRP Annals - Manufacturing Technology 63(2): 703-726.

[11] Li H.Y, Klocke F, Zeis M, Herrig T, Heidemanns L (2018) Experimental Study on the ECM and PECM of Pressed and Casted $\gamma$-TiAl Alloys for Aero Engine Applications. Procedia CIRP 68: 768-771.

[12] Anasane S.S, Bhattacharyya B (2019) Parametric analysis of fabrication of through micro holes on titanium by maskless electrochemical micromachining. The International Journal of Advanced Manufacturing Technology 105(1) : 4585-4598.

[13] Ma N, Yang XL, Gao MQ, Song JL, Liu GL, Xu WJ (2015) A study of electrodischarge machining-pulse electrochemical machining combined machining for holes with high surface quality on superalloy. Advances in Mechanical Engineering 7(11):1-11.

[14] Sathish T (2019) Experimental investigation of machined hole and optimization of machining parameters using electrochemical machining. Journal of Materials Research and Technology 8(5):4354-4363.

[15] Zhao JS, Wang F, Liu Z, Zhang XL, Gan WM, Tian ZJ (2016) Flow field design and process stability in electrochemical machining of diamond holes. Chinese Journal of Aeronautics 29(06):1830-1839.

[16] Zhao JS, Zhang XL, Yang ZW, Lü YM, He YF (2017) Experimental research on the optimization of precision electrochemical machining feed mode of diamond-hole grille. The International Journal of Advanced Manufacturing Technology 91(1-4):147-153.

[17] Zhu XM, Liu Y, Zhang JH, Wang K, Kong HH (2020) Ultrasonic-assisted electrochemical drill-grinding of small holes with high-quality. Journal of advanced research 23:151-161.

[18] Sarkar B.R, Doloi B, Bhattacharyya B, Tayade R.M (2019) Experimental Investigation Into Sequential Micro Machining (SMM) for Micro Hole Drilling on SS-304. International Journal of Manufacturing, Materials, and Mechanical Engineering 9(4):1-16

[19] Xu ZY, Zhang CX (2018) A Tube Electrode High-speed Electrochemical Discharge Drilling Method without Recast Layer. Procedia CIRP 68:778-782.

[20] Chakradhar D, Gopal V.A (2011) Multi-objective Optimization of Electrochemical Machining of EN31 Steel by Grey Relational Analysis. International Journal of Modeling and Optimization 1(2):113-117.

[21] Koyano T, Hosokawa A, Takahashi T, Ueda T (2019) One-process surface texturing of a large area by electrochemical machining with short voltage pulses. CIRP Annals - Manufacturing Technology 68(1):181-184

[22] Demirtas H, Yilmaz O, Kanber B (2019) Experimental investigation of the effects of dedicated electrochemical machining parameters on freeform surface machining. Journal of Manufacturing Processes 43:244-252

[23] Uchiyama M, Kunieda M (2013) Application of large deflection analysis for tool design optimization in an electrochemical curved hole machining method. Precision Engineering 37(3):765-770. 
[24] Burger M, Koll L, Werner E A, Platz A (2012) Electrochemical machining characteristics and resulting surface quality of the nickel-base single-crystalline material LEK94. Journal of Manufacturing Processes 14(1):62-70.

[25] Mi DH, Wataru N (2015) Proposal of ECM method for holes with complex internal features by controlling conductive area ratio along tool electrode. Precision Engineering 42:179-186.

[26] Kong QC, Liu GL, Song JL, Tan QF, Liu GZ, Zhao SQ (2021) Preparation of sidewall-insulation layer on micro-hollow electrodes for ECM by asymmetric-timed bipolar electrophoretic coating method and its application. Precision Engineering 67:24-35.

[27] Li ZL, Wei DB, Di SC, Lv PX, Sun SF (2012) Research on Shaped-tube Electrode Machining Turbulated Hole by Pulse Electrochemical Machining. Acta Armamentarii 33 (02): 197-202. (in Chinese)

[28] Fan ZW, Hourng LW (2009) The analysis and investigation on the microelectrode fabrication by electrochemical machining. International Journal of Machine Tools \& Manufacture 49(7-8):659-666.

[29] Selvarajan L, Sasikumar R, Mohan Dhanesh G, Naveen Kumar P, Muralidharan V (2020) Investigations on electrochemical machining (ECM) of Al7075 material using copper electrode for improving geometrical tolerance. Materials Today: Proceedings 27(Pt 3): 2708-2712.

[30] Ramezanali M; Mohammadreza H (2008) On the Application of Electrochemical Machining for Inner Surface Polishing of Gun Barrel Chamber. Journal of Materials Processing Technology 202: 307-315.

[31] Liu GX, Zhang YJ, Natsu W (2019) Influence of electrolyte flow mode on characteristics of electrochemical machining with electrolyte suction tool. International Journal of Machine Tools and Manufacture 142:66-75.

[32] Hu XY, Zhu D, Li JB, Gu ZZ (2019) Flow field research on electrochemical machining with gas film insulation. Journal of Materials Processing Tech (267):247-256.

[33] Li JZ, Wang DY, Zhu D, He B (2020) Analysis of the flow field in counter-rotating electrochemical machining. Journal of Materials Processing Tech 275. 